07,10

\title{
Особенности структуры карбида бора после приложения сдвиговых деформаций под давлением до $55 \mathrm{GPa}$
}

\author{
(C) М.Р. Анненков ${ }^{1,2}$, Б.А. Кульницкий ${ }^{1,2, q}$, И.А. Пережогин ${ }^{1-3}$, \\ Д.А. Овсянников ${ }^{1}$, М.Ю. Попов ${ }^{1,2,4}$, В.Д. Бланк ${ }^{1,2,4}$ \\ ${ }^{1}$ Технологический институт сверхтвердых и новых углеродных материалов, \\ Москва, Троицк, Россия \\ ${ }^{2}$ Московский фризико-технический институт (Государственный университет), \\ Долгопрудный, Россия \\ ${ }_{3}^{3}$ Московский государственный университет им. М.В. Ломоносова, \\ Москва, Россия \\ ${ }^{4}$ Национальный исследовательский технологический университет „МИСиС“, \\ Москва, Россия \\ IE-mail: boris@tisnum.ru
}

(Поступила в Редакцию 20 июля 2016 г.

В окончательной редакции 26 сентября 2016 г.)

Методами просвечивающей электронной микроскопии исследованы структурные особенности карбида бора, обработанного в камере высокого давления типа алмазных наковален со сдвигом в диапазоне давлений 25 -55 GРа. Показано, что такая обработка приводит к образованию трещин преимущественно по плоскостям $\{10 \overline{1} 1\}$ и $\{10 \overline{1} 2\}$, а также возникновению политипов в плоскостях $\{10 \overline{1} 1\}$ и деформационных полос в плоскостях $\{10 \overline{1} 2\}$.

DOI: 10.21883/FTT.2017.05.44379.301

\section{1. Введение}

Карбид бора $\left(\mathrm{B}_{4} \mathrm{C}\right)$ представляет значительный интерес для научных исследований и практических приложений, так как отличается широким набором перспективных химических, физических и механических свойств [1]. Карбид бора является твердым, прочным и легким материалом с широким спектром применения. Он используется в качестве примесей в металлических и полуметаллических композитах, в качестве материала для износостойких и абразивных деталей, в военной технике. Наиболее значимыми характеристиками карбида бора являются прочностные свойства, поэтому использование $\mathrm{B}_{4} \mathrm{C}$ часто связано с высокоинтенсивными ударными нагрузками. Процессы деформации $\mathrm{B}_{4} \mathrm{C}$, в том числе испытания методом склерометрии, были исследованы в ряде работ [2-6]. Изучены структурные превращения карбида бора при статическом [2-4] и динамическом индентировании $[5,6]$.

Особенности структуры после различных обработок рассмотрены в $[1,7,8]$. В частности, были изучены двойники в карбиде бора [7]. Анализ условий нагрузки исследуемых образцов позволяет предположить, что двойникование частично объясняется наличием высоких локальных напряжений и сдвиговых деформаций в процессе обработки. При сжатии в карбиде бора деформации возникают вдоль направления [0001] [1]. С помощью электронно-микроскопических исследований был оценен механизм образования дефектов решетки карбида бора при ударной нагрузке, создаваемой частицами, бомбардирующими баллистическую мишень и тем самым оказывающими давление в 20-23 GPa [8]. Там же было показано, что аморфные полосы образуются параллельно определенным кристаллографическим плоскостям. При превышении критических значений аморфные полосы уже не наблюдаются, а вместо них образуются двойники и дефекты упаковки с высокой относительной плотностью.

В настоящей работе проведены исследования механизмов деформации карбида бора методом сдвига под давлением с использованием алмазных наковален. Эксперименты проведены при различных давлениях в диапазоне 25-55 GPa. Целью работы является изучение структурных особенностей карбида бора, появляющихся при такой обработке.

\section{2. Эксперимент}

Исследования $\mathrm{B}_{4} \mathrm{C}$ проводились под давлением в сдвиговой камере с алмазными наковальнями, подробно описанной в работе [9]. Исходный материал $\mathrm{B}_{4} \mathrm{C}$ загружался в стальную гаскету, диаметр отверстия в которой составлял половину диаметра рабочей поверхности наковальни (диаметр рабочей площадки алмазных наковален от 0.3 до $0.5 \mathrm{~mm})$. В экспериментах использовался карбид бора в виде порошка с зернистостью $15 \mu \mathrm{m}$ (марка 1B). Образцы нагружались до давления 25-55 GPa. После достижения заданного давления образцы подвергались сдвиговой деформации путем поворота наковален относительно друг друга вокруг оси нагрузки. Угол поворота во всех случаях составлял $90 \pm 5^{\circ}$. Полученные образцы исследовались методами просвечивающей электронной 

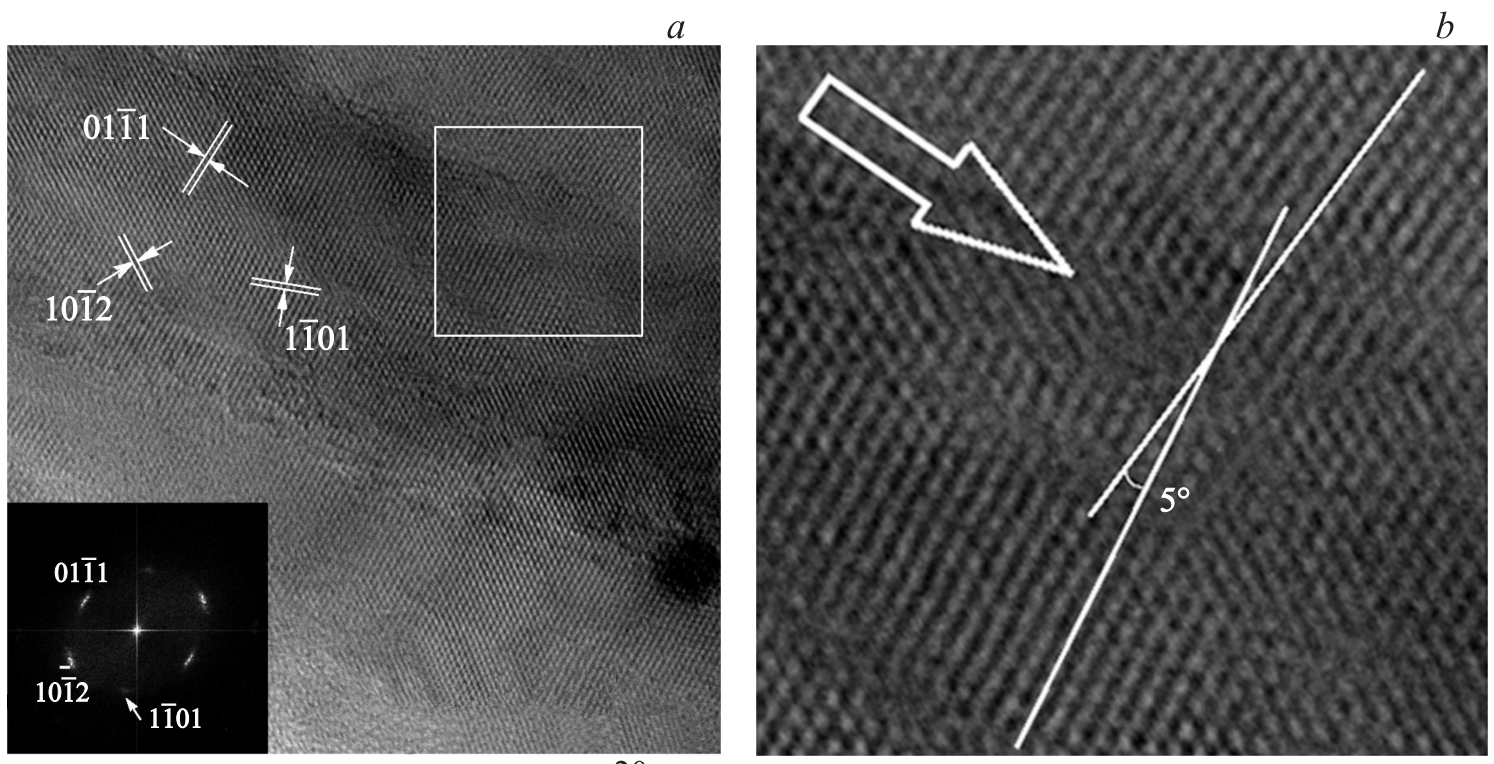

Рис. 1. Образец карбида бора, обработанный под давлением $25 \mathrm{GPa}$. $a$ - следы деформации параллельные плоскости $(1 \overline{1} 01)$; на вставке в левом нижнем углу изображения приведен его Фурье-образ, на котором обозначены индексы узлов обратного пространства. $b$ - увеличенное изображение фрагмента, отмеченного на части $a$. Малоугловая граница. Направление распространения полос указано стрелкой $b$. Плоскость, в которой лежат дефекты, примерно совпадает с плоскостью (11ㅣ).

микроскопии (ПЭМ) на приборе JЕМ 2010, оснащенном оборудованием для регистрации спектров характеристического рентгеновского излучения (EDS) и спектров потерь энергии электронов. Для ПЭМ-исследований образцы готовились на предметном стекле с помощью иголок. При этом происходило разделение образца на мелкие фрагменты. После этого полученные фрагменты наносились на ПЭМ-сетку с напыленной на нее аморфной пленкой углерода для дальнейшего исследования в микроскопе.

\section{3. Результаты}

Как известно, кристаллическая решетка карбида бора может быть представлена двумя способами: в ромбоэдрических координатах с параметрами $a=0.516 \mathrm{~nm}$ и $\alpha=65.7^{\circ}$ и в гексагональных координатах с параметрами $a=0.56 \mathrm{~nm}, c=1.207 \mathrm{~nm}[1]$. В настоящей работе были использованы гексагональные координаты.

Отличительной особенностью исследованных образцов карбида бора была высокая дефектность структуры. В образцах, обработанных в алмазных наковальнях со сдвигом под давлением 25 и $35 \mathrm{GPa}$, были обнаружены нарушения структуры: различного рода дефекты, лежащие в плоскостях $\{10 \overline{1} 1\}$ и $\{10 \overline{1} 2\}$, тогда как при исследовании карбида бора, обработанного в алмазных наковальнях со сдвигом при более высоком давлении $(55 \mathrm{GPa})$, были обнаружены только полосы деформации в плоскостях $\{10 \overline{1} 2\}$. Ширина этих деформационных полос не превышает $2 \mathrm{~nm}$ и они выделяются контрастом. Все описанные выше дефекты отсутствовали в исходных образцах, которые также были исследованы методом ПЭМ.

На рис. 1 и 2 показана дефектная структура кристалла карбида бора, обработанного под давлением $25 \mathrm{GPa}$ в сдвиговой камере типа алмазных наковален. При анализе полученных данных обнаружено, что найденные дефекты в основном лежат в плоскостях $\{10 \overline{1} 1\}$ (рис. 1,2) и

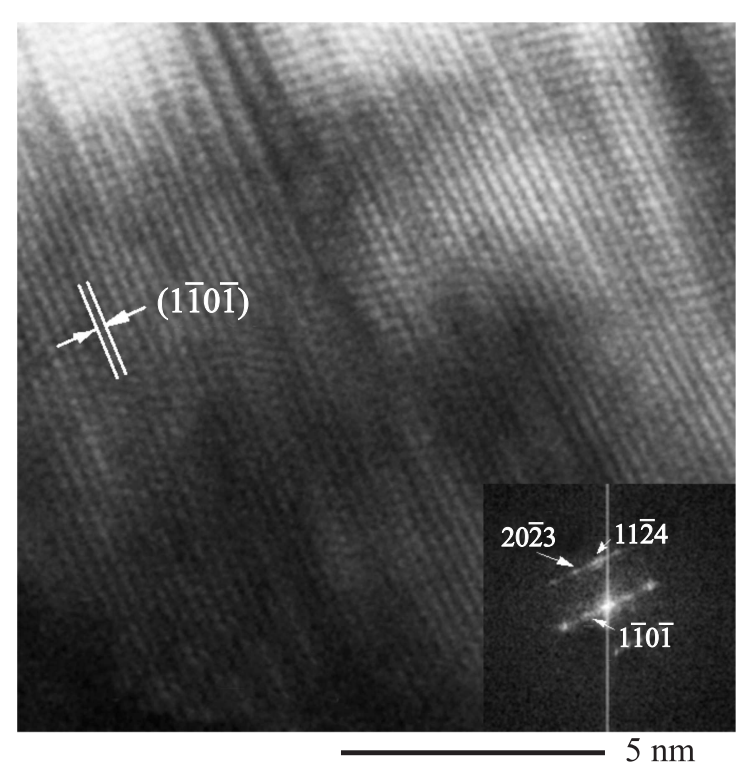

Рис. 2. Образец карбида бора, обработанный под давлением $25 \mathrm{GPa}$ политипы в плоскости $(1 \overline{1} 0 \overline{1})$. На вставке Фурье-образ, на котором обозначены индексы узлов обратного пространства. 


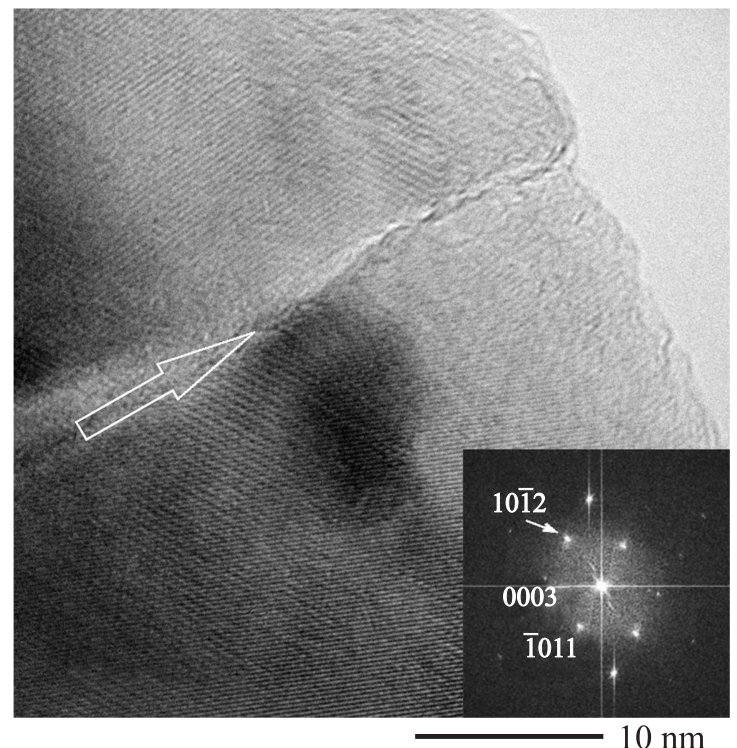

Рис. 3. Образец карбида бора, обработанный под давлением $35 \mathrm{GPa}$. Трещина в плоскости (1012). На вставке Фурье-образ, на котором обозначены индексы узлов обратного пространства.

$\{10 \overline{1} 2\}$ : из двадцати проанализированных дефектов в шести случаях наблюдается параллельность $\{10 \overline{1} 1\}$ и в девяти случаях параллельность $\{10 \overline{1} 2\}$. На рис. 1 видны параллельные слегка искаженные полосы, напоминающие трещины. Кристаллическая структура справа и слева от полос одинакова, что видно из соответствующего Фурьепреобразования изображения (см. вставку на рис. $1, a$ ).
Рефлексы на нем немного уширены. Это связано с разориентацией фрагментов кристаллической решетки в пределах изображения. На рис. $1, b$ показано увеличенное изображение фрагмента, отмеченного на рис. $1, a$. Видно, что в результате деформации образовалась малоугловая граница. Угол между соседними фрагментами составляет примерно $5^{\circ}$. Направление распространения полос указано стрелкой (рис. $1, b)$. Плоскость, в которой лежат дефекты, примерно совпадает с плоскостью (11̄01). На рис. 2 отчетливо видны политипы по плоскости $(1 \overline{1} 0 \overline{1})$. Об этом свидетельствуют и тяжи на соответствующем Фурье-преобразовании. Таким образом, деформация карбида бора в алмазных наковальнях под давлением $25 \mathrm{GPa}$ осуществляется преимущественно путем образования малоугловых границ и политипии в плоскостях $\{10 \overline{1} 1\}$.

При исследовании образца карбида бора, обработанного при давлении $35 \mathrm{GPa}$, также были обнаружены дефекты, при этом из десяти исследованных дефектов в шести случаях наблюдалась параллельность преимущественно плоскости $\{10 \overline{1} 2\}$, а в трех случаях - плоскости $\{10 \overline{1} 1\}$. На рис. 3 показана структура, полученная в этом случае. Отчетливо видна трещина, лежащая в плоскости (101̄2).

На рис. 4 представлены деформационные полосы, параллельные плоскостям $\{10 \overline{1} 2\}$, возникающие в образце, обработанном при $55 \mathrm{GPa}$. На приведенном изображении высокого разрешения видно, что полосы деформации параллельны друг другу и различаются по контрасту, расстояние между ними составляет около $7 \mathrm{~nm}$, а сами полосы достаточно узкие (около 1-2 nm). Рис. 4, $b$ представляет собой увеличенное изображение фрагмента, отмеченного на рис. 4,a. Стрелками показаны плос-
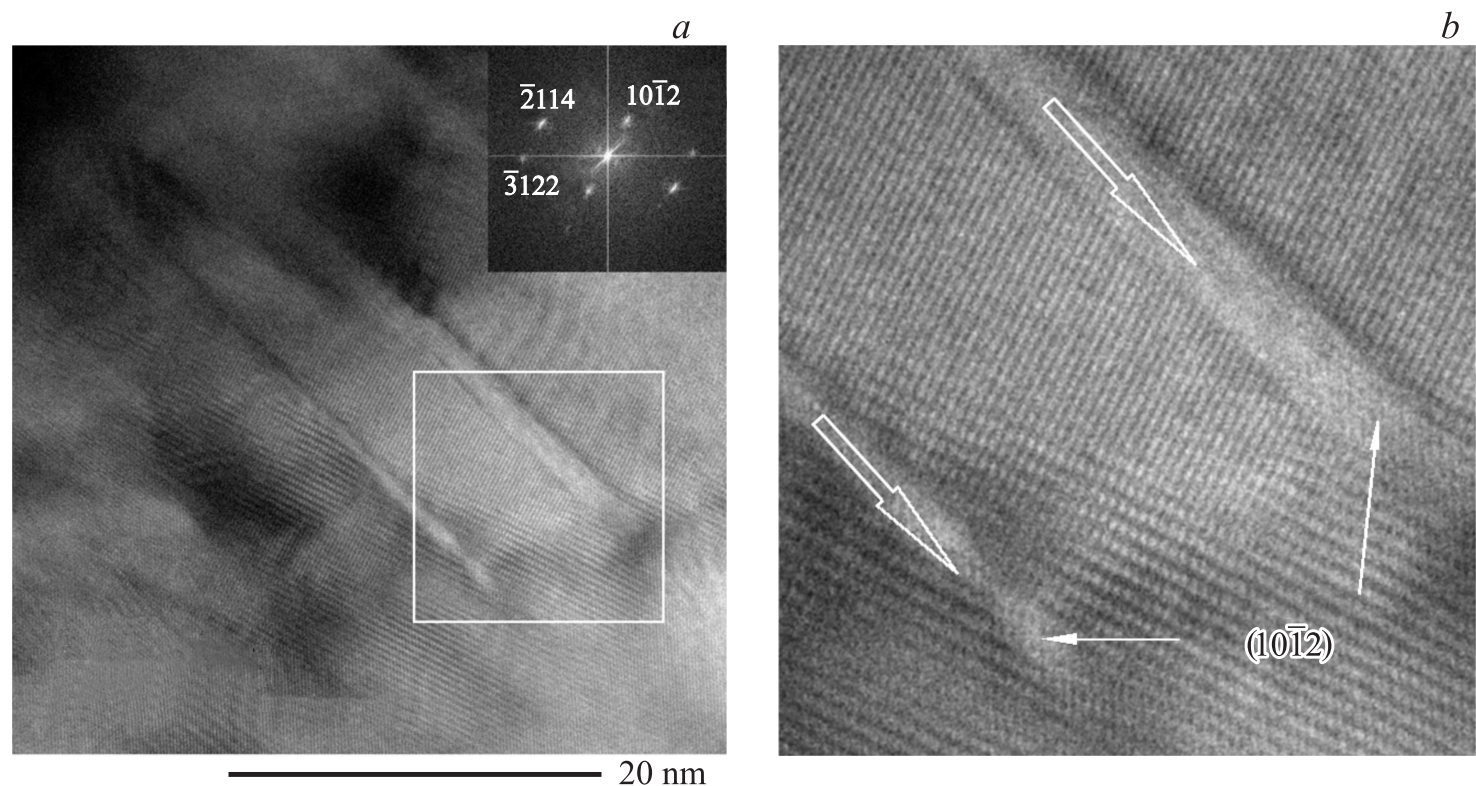

Рис. 4. Образец карбида бора, обработанный под давлением $55 \mathrm{GPa}$. $a$ - на изображении видны аморфные деформационные полосы, параллельные плоскости (1012). На вставке - Фурье-образ, на котором обозначены индексы узлов обратного пространства. $b-$ увеличенный фрагмент изображения, выделенный на части $a$ светлым квадратом. Широкие стрелки показывают направление аморфных полос. 


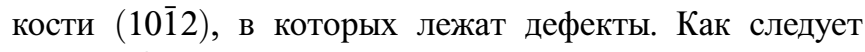
из рис. $4, b$, в таких полосах кристаллическая решетка не просматривается. Подобные полосы в литературе принято определять как аморфные.

\section{4. Обсуждение результатов}

Дефекты в карбиде бора, обработанном в планетарной мельнице, исследовались в [10]. Была проведена серия экспериментов по изучению дефектов в структуре карбида бора после обработки в планетарной мельнице в составе композита с $\mathrm{Si}$ и чистого карбида бора при различном времени размола [10]. Было обнаружено, что обработка карбида бора в планетарной мельнице ведет к измельчению частиц и образованию трещин по плоскостям $\{20 \overline{2} 1\}$.

Таким образом, в отличие от [10] в настоящей работе трещины в образцах карбида бора, обработанных в алмазных наковальнях со сдвигом, в основном параллельны плоскостям $\{10 \overline{1} 1\}$ и $\{10 \overline{1} 2\}$, тогда как в $[10]$ они лежали в плоскостях $\{20 \overline{2} 1\}$ (а в плоскостях $\{10 \overline{1} 1\}$ происходило двойникование).

Деформационные полосы, подобные обнаруженным нами, наблюдались и в ряде других работ после различных способов обработки, например при исследовании фуллерита $\mathrm{C}_{60}$ после термобарической обработки [11] и при исследовании фуллеренов после обработки в алмазной камере [12]. Обычно в литературе эти полосы считаются аморфными.

Полосы деформации образуются в различных материалах: горных породах, металлах $[13,14]$, ионных кристаллах, органических соединениях, полимерах [15], поликристаллических сплавах [14,16-18] и металлических стеклах $[19,20]$, подвергнутых пластической деформации. Полосы локализуются в областях, где образец претерпел сдвиговую деформацию. Локализация сдвига является одним из основных способов деформации и встречается довольно часто в различных материалах при динамических нагрузках, а также при монотонном растяжении и испытаниях на усталость $[17,18]$. Появление полос деформации, как и образование трещин различного размера [15], является следствием неупругой реакции материала на механическую нагрузку. В полосах могут происходить фазовые превращения, рекристаллизация, a также переход из кристаллического состояния в разупорядоченное или аморфное [21]. Появление полос сопровождается образованием рельефа на поверхности образца [14].

Существуют разные объяснения появления полос деформации. Так, считается, что интерференция волн разгрузки создает области растягивающих напряжений. Трещины зарождаются в тех участках, где величина растягивающих напряжений превышает динамический предел прочности материала. По мере углубления трещины интенсивность растягивающих напряжений снижается, и трещины перерастают в полосы адиабатического сдвига [22].
При исследовании дефектности карбида бора установлено, что он деформируется на атомарном уровне с образованием аморфной полосы [23]. В [8] наблюдалось образование внутризеренных аморфных полос шириной $2-3 \mathrm{~nm}$. Степень деформации при этом влияет на появление полос деформаций. Там же было продемонстрировано, что аморфные полосы параллельны плоскости (11) 3$)$. Аморфная фаза является следствием структурного разрушения, связанного с изгибанием цепочки из трех атомов [24]. В решетке карбида бора помимо отдельных атомов бора и углерода выделяют также икосаэдры, состоящие из двенадцати атомов бора. Считается, что процесс аморфизации происходит по двум механизмам. Неэмпирические вычисления [24] показали, что после аморфизации икосаэдры все еще опознаваемы, но сильно искажены из-за образования новых связей между сжатыми атомами из цепочки. Это свидетельствует о том, что изгибание цепочки, состоящей из трех атомов, является основным признаком аморфизации. Авторы [4] заключили, что разрушение цепочки из трех атомов (C-B-C) приводит к аморфной структуре. Образование аморфных полос деформации в результате разрушения икосаэдров на ромбоэдрические единичные элементы в процессе сдвиговой деформации наблюдалось в [25]. В [26] утверждается, что аморфизация карбида бора может быть в основном достигнута за счет структурных изменений цепочек $\mathrm{C}-\mathrm{B}-\mathrm{C}$ с небольшим количеством бора в цепочках, находящихся в ароматических кольцах, путем его замены на углерод с сохранением структуры икосаэдров. Характерных для пластических деформаций дислокаций, дефектов упаковки или двойников вокруг аморфных зон обнаружено не было; данный факт позволяет предположить, что двойникование и образование дефектов не являются необходимыми условиями для аморфизации [8].

Неожиданным результатом работы можно считать то, что мы не наблюдали реального разрушения карбида бора. Мы обнаружили образование малоугловых границ и политипию по плоскости $\{10 \overline{1} 1\}$, а также трещины и аморфные полосы по плоскости $\{10 \overline{1} 2\}$. Прочность карбида бора объясняется особенностями кристаллической решетки этого материала. Так, икосаэдры, содержащие по двенадцать атомов бора, соединенные цепочками, состоящими из трех атомов углерода, образуют прочную кристаллическую решетку. Считается, что в процессе деформации происходит искажение икосаэдров, но никак не их разрушение.

\section{5. Заключение}

Методами электронной микроскопии исследован карбид бора, деформированный в сдвиговой камере высокого давления типа алмазных наковален в широком диапазоне давлений (25-55 GPa). Обнаружены следующие особенности структуры карбида бора после обработки: малоугловые границы и политипия по плоскостям $\{10 \overline{1} 1\}$ при давлении $25 \mathrm{GPa}$, трещины по плоскостям $\{10 \overline{1} 2\}$ при обработке под давлением $35 \mathrm{GPa}$ и аморфные деформационные (узкие порядка $2 \mathrm{~nm}$ ) полосы в плоскостях $\{10 \overline{1} 2\}$ при обработке под давлением $55 \mathrm{GPa}$. 
Появление дефектов, лежащих в указанных кристаллографических плоскостях связано с разницей в энергии их образования в зависимости от индексов плоскости. Возникновение полос деформации происходит из-за интерференции волн разгрузки в тех участках, где, повидимому, величина растягивающих напряжений превышает динамический предел прочности материала.

\section{Список литературы}

[1] V. Domnich, S. Reynaud, R.A. Haber, M. Chhowalla. J. Am. Ceram. Soc. 94, 3605 (2011).

[2] D. Ge, V. Domnich, T. Juliano, E.A. Stach, Y. Gogotsi. Acta Mater 52, 3921 (2004).

[3] V. Domnich, Y. Gogotsi, M. Trenary, T. Tanaka. Appl. Phys. Lett. 81, 3783 (2002).

[4] X.Q. Yan, W.J. Li, T. Goto, M.W. Chen. Appl. Phys. Lett. 88, 131905 (2006).

[5] D. Ghosh, G. Subhash, C.H. Lee, Y.K. Yap. Appl. Phys. Lett. 91, 061910 (2007).

[6] D. Ghosh, G. Subhash, T.S. Sudarshan, R. Radhakrishnan, X.L. Gao. J. Am. Ceram. Soc. 90, 1850 (2007).

[7] Y. Li, Y.H. Zhao, W. Liu, Z.H. Zhang, R.G. Vogt, E.J. Lavernia, J.M. Schoenung. Phil. Mag. 90, 783 (2010).

[8] M. Chen, J.W. McCauley, K.J. Hemker. Science 299, 1563 (2003).

[9] V.D. Blank, A.J. Zerr. High Press Res. 8, 567 (1992).

[10] M. Annenkov, V. Blank, B. Kulnitskiy, K. Larionov, D. Ovsyannikov, I. Perezhogin, M. Popov, P. Sorokin. J. Eur. Ceram. Soc., 37, 1349 (2017).

[11] V.D. Blank, Ye.V. Tatyanin, B.A. Kulnitskiy. Phys. Lett. A 225, 121 (1997).

[12] B.A. Kulnitskiy, V.D. Blank, V.I. Levitas, I.A. Perezhogin, M.Yu. Popov, A.N. Kirichenko, E.V. Tyukalova. Mater. Res. Express 3, 045601 (2016).

[13] T.W. Wright. In: Adiabatic shear localization. 2nd ed. Elsevier, Amsterdam (2012) P. 215.

[14] B.K. Sokolov, V.V. Gubernatorov, I.V. Gervasyeva, A.K. Sbitnev, L.R. Vladimirov. Textures Microstruct. 32, 21 (1999).

[15] J.C.M. Li. Polym. Eng. Sci. 24, 750 (1984).

[16] V. Blank, S. Buga, M. Popov, V. Davydov, V. Agafonov, R. Ceolin, H. Szwarc, A. Rassat, G. Fabre. New J. Chem. 19, 253 (1995).

[17] Y.B. Xu, L. Wang, Y. Zhang, Z.G. Wang, Q.Z. Hu. Metall. Mater. Trans. A 22, 723 (1991).

[18] Y.B. Xu, L. Wang, Z.G. Wang, Y. Zhang, Z.Q. Hu. Scripta Met. Mater. 25, 1149 (1991).

[19] G. Xiaofeng, W. Jun, Q. Weidong, K. Hongchao, L. Jinshan, Z. Lian. Rare Met. Mater. Eng. 39, 941 (2010).

[20] J.J. Lewandowski, A.L. Greer. Nature Mater. 5, 15 (2006).

[21] H.J. Yang, J.H. Zhang, Y.B. Xu, M.A. Meyers. J. Mater. Sci. Technol. 24, 819 (2008).

[22] А.Ф. Беликова, С.Н. Буравова, Ю.А. Гордополов. ЖТФ 83, 2, 153 (2013).

[23] Q. An, W.A. Goddard III, T. Cheng. Phys. Rev. Lett. 113, 095501 (2014).

[24] S. Aryal, P. Rulis, W.Y. Ching. Phys. Rev. B 84, 184112 (2011).

[25] K.M. Reddy, P. Liu, A. Hirata, T. Fujita, M.W. Chen. Nature Commun. 4, 2483 (2013).

[26] X.Q. Yan, Z. Tang, L. Zhang, J.J. Guo, C.Q. Jin, Y. Zhang, T. Goto, J.W. McCauley, M.W. Chen. Phys. Rev. Lett. 102, 075505 (2009). 